\title{
Simple Retinoscopic Screening
}

\author{
J M OLVER \\ Cardiff
}

\begin{abstract}
Summary
A simplified retinoscopic technique to screen for refractive errors in children is presented. The technique described was assessed in 98 children and the results correlated with full retinoscopic refractions. All tests were done with cycloplegia. Orthoptists' results using the simple retinoscopy compared well with the full retinoscopic findings of the ophthalmologists, with an overall sensitivity of $90 \%$ and specificity of $74 \%$. These results compare favourably with more technical refractive screening methods.
\end{abstract}

This technique may be suitable as an adjunct to vision screening in pre-school children.

Why screen?

Ingram in $1977^{1}$ reviewed cases of strabismus and amblyopia seen in one year and found that $75 \%$ of amblyopes identified after the age of 5 years had no detectable deviation clinically and suggested that a screening test was required to identify this group of 'straight eyed amblyopes' at an earlier age and thus prevent the amblyopia. He refracted a sample of children with esotropia and/or amblyopia ${ }^{2}$ and found a significant association with hypermetropia of +2.0 DS or more and/or anisometropia of a similar amount. He therefore recommended considering refraction as a screening procedure. In $1979^{3}$ he reported the effective use of full cycloplegic refraction in one year old children and a correlation of hypermetropia of +2.5 DS or more at this age with the development of later amblyopia and/or strabismus.

However, Ingram ${ }^{4}$ found that spectacle correction of very high hypermetropia from the age of one year did not reduce the severity of amblyopia or incidence of strabismus, and suggested ${ }^{5}$ that proposed screening at age three years for mild refractive errors has yet to be evaluated on a larger scale than his study population, perhaps by photorefraction. Ideally, if planning a refractive screening programme it should be demonstrable that the treatment offered is beneficial $-i e$ that spectacle correction at an early age does reduce the prevalence of amblyopia and strabismus in the community. This would require a well planned prospective randomised trial. This is being done by Atkinson and preliminary reports (unpublished) suggest that spectacle corrected hyperopic infants do have a significantly lower incidence of strabismus and amblyopia than untreated hypermetropic infants.

Taylor $^{6}$ has argued that only bilateral visual handicap is socially significant and debilitating, whereas unilateral amblyopia is rarely debilitating unless there is injury to the other eye which is uncommon as shown by Tommila and Tarkkanen. ${ }^{7}$ Taylor therefore recommends caution when considering a screening program lest it be cost ineffective and divert resources from important research in to the cause of amblyopia.

How to screen?

Having decided to screen for refractive errors

From, University Hospital of Wales, Cardiff

Correspondence to: Jane M Olver FRCS, Moorfields Eye Hospital, City Road, London EC1V 2PD

Presented at the Annual Congress of the Ophthalmological Society of the United Kingdom, April 1987 
Table I Previously described methods of screenings for refractive errors

RETINOSCOPIC

FULL RETINOSCOPY

RAPID RETINOSCOPY

NEAR RETINOSCOPY

PHOTOGRAPHIC

Photographic screening.

Otago photoscreener.

Photorefraction.
Ingram.

Friedman et al.

Mohindra.

Kaakinen

Molteno et al.

Atkinson et al.
Use of Cycloplegia

(3)

(8)

(9)
$+$

$-$

$-$ the methods available include retinoscopic $^{3,8,9}$ and photorefractive. ${ }^{10,11,12}$ (See Table I).

Ingram $^{3}$ used full cycloplegic retinoscopy as a screening technique and found it impractical as it was lengthy, and hence costly in terms of personnel.

Friedman et al $l^{8}$ used rapid retinoscopy on 38,000 small children without cycloplegia and without trial lenses. This had a high false positive rate of almost $52 \%$.

Mohindra $^{9}$ described a near retinoscopy technique without cycloplegia performed with monocular fixation at $50 \mathrm{cms}$ on the dim retinoscopy light and employing trial lenses. Mohindra's near refraction correlates well with full retinoscopy and is a possible alternative method for screening although it has not been used as such.

The photorefractive methods use relatively expensive equipment and correlate well with full retinoscopic refractions.

The photorefractive 'camera flash' technique used by Kaakinen ${ }^{10}$ can screen for both strabismus and refractive errors by photography of corneal and fundus reflexes without cycloplegia. The accuracy is increased with cycloplegia.

The Otago photoscreener ${ }^{11}$ also uses a camera to detect both strabismus and refractive errors without the use of cycloplegia.

Isotropic photorefraction by Atkinson et $a l^{12}$ uses three photographs, one of the pupils and two with set values of defocus to produce 'blur circles', the size of which are used to calculate focusing and hence refractive status of the eye. Cycloplegia is not usually used.

Photorefraction has proved an invaluable research tool in vision research greatly con-
Table II

\section{Basic equipment}

guttae cyclopentolate $1 \%$ streak retinoscope plus 3 ds lens

tributing to our knowledge of the type and changes of refraction with age in children. ${ }^{13,14}$ However, photorefraction has not found widespread application as a screening method in this country. The methods are technical, require interpretation and may be costly, e.g. video photorefraction.

\section{Who should do the screening?}

Orthoptists are already involved in vision screening programmes for the detection of amblyopia and squint. This role might appropriately be extended to include screening for refractive errors which can be significant in the development of amblyopia and strabismus.

The aim of this study was to see if orthoptists could use a simple retinoscopic screening technique, to detect refractive errors in children; it does not question the rationale for screening, only offers a possible method.

\section{Methods}

Ninety-eight consecutive children, aged 6 months to 11 years, median 2 years, newly referred to the Orthoptic Department in Cardiff were screened for refractive errors by an orthoptist using simplified retinoscopy under cycloplegia. (See Table II for basic equipment used). Those children found to have refractive errors were placed into four categories according to defined criteria 
Table III Criteria used for diagnostic classification

\begin{tabular}{|c|c|}
\hline 1 MYOPIA & $\begin{array}{l}\text { Light reflex AGAINST } \\
\text { movement without any } \\
\text { lens. } \\
\text { THRESHOLD }-1.5 \text { DS }\end{array}$ \\
\hline 2 HYPERMETROPIA: & $\begin{array}{l}\text { Light reflex WITH } \\
\text { movement with + 3.0DS } \\
\text { lens. } \\
\text { THRESHOLD + } 1.5 \mathrm{DS}\end{array}$ \\
\hline 3 ASTIGMATISM & $\begin{array}{l}\text { Light reflex } \\
\text { DIFFERENT between } \\
\text { vertical and horizontal } \\
\text { axis. } \\
\text { THRESHOLD + } 0.5 \text { D }\end{array}$ \\
\hline 4 ANISOMETROPIA: & $\begin{array}{l}\text { Light reflex } \\
\text { DIFFERENT between } \\
\text { eyes. } \\
\text { THRESHOLD + } 0.5 \mathrm{D}\end{array}$ \\
\hline
\end{tabular}

(Table III). The simple retinoscopic test uses a streak retinoscope first without and then with a plus 3.0 DS lens both in the horizontal and vertical meridian of each eye. The orthoptist was asked simply to note the direction of movement of the retinoscopic shadow in each of the four test situations on each eye, thus detecting approximately myopia or hypermetropia exceeding $1.5 \mathrm{D}$ and anything more than a small astigmatic error or anisometropia.

Each child was then refracted by an ophthalmologist. All tests were performed in a dim room at a working distance of $2 / 3 \mathrm{~m}$ under cyclopentolate $1 \%$ cycloplegia. Neither the orthoptist nor the ophthalmologist had prior information on the child or of each other's findings. The refractive classifications by the orthoptists using simple retinoscopy were compared with the full retinoscopic refractions by the opthalmologists and the sensitivity and specificity of the orthoptist's screening were computed. The McNemar test was used to assess the significance of differences.

\section{Results}

The results are presented in Tables IV and V.

The orthoptists were good at detecting children with significant refractive errors; they missed $4 / 93(4.3 \%)$. The significant difference overall between the orthoptist and ophthalmologist was due to overdiagnosis 14/ $93(15 \%)$ which was particularly true for hypermetropia and astigmatism.

The number of unco-operative children was $5 / 98(5.1 \%)$ who were all infants. The results of repeat screening of these children are not included in the Tables.

\section{Discussion}

The results using simple retinoscopy compare favourably with other methods of screening described. It is not possible to compare all the methods directly because the data presented are not always in a similar form and the refractive thresholds selected differ slightly. (Table VI).

In this study using simple retinoscopy + $1.5 \mathrm{D}$ was allowed for working distance with no subtraction made for cycloplegia. Hence, when using either no lens in front of the child a threshold of $-1.5 \mathrm{DS}$ is detected and with a +3.0 DS lens a refractive threshold of $+1.5 \mathrm{DS}$. The orthoptists detected low amounts of astigmatism and anisometropia easily.

Eleven orthoptists participated in the study after receiving a brief instruction period; their individual relative inexperience contributed initially to the number of false negatives which decreased with their increasing expertise as the study progressed. Inadequate cycloplegia probably contributed to a small number of false negatives. The over-referral rate of $15 \%$ (false positives) included children with off axis retinoscopy. These are practical points which once recognised can be avoided. The rate of overdiagnosis is acceptable for a screening method especially as it should reduce with practice.

Rapid retinoscopy by Friedmann ${ }^{8}$ without cycloplegia has a false positive rate of almost $52 \%$. Photorefraction using Kaakinen's method without cycloplegia ${ }^{15}$ had a low false positive rate and the small number of false negatives were of low refractive errors. The test without cycloplegia gives approximate values, not absolutes, and has a blind refractive interval between -3.0 and +1.0 D.S. The Otago Photoscreener ${ }^{11}$ had a false positive rate of approximately $5 \%$ ( 8 children) when unco-operative children were excluded and no false negatives. This photorefractive 
Table IV Simple retinoscopy results by orthoptists

\begin{tabular}{lcccc}
\hline \multicolumn{5}{c}{93 patients. (98 children in study, 5 unco-operative) } \\
\hline True +ve & False +ve & True - ve & False - ve \\
Overall & 36 & 14 & 39 & 4 \\
Myopia & 2 & 3 & 88 & 0 \\
Hypermetropia & 33 & 10 & 46 & 4 \\
Astigmatism & 13 & 13 & 66 & 1 \\
Anisometropia & 10 & 4 & 75 & 4 \\
\hline
\end{tabular}

Where: True + ve means refractive error present

False + ve means refractive error falsely diagnosed as present

True - ve means no refractive error present

False - ve means refractive error missed

Table $\mathbf{V}$ Results of simple refractions by orthoptists compared to full refractions by ophthalmologists and significance of differences

\begin{tabular}{lcll}
\hline & SENSITIVITY & SPECIFICITY & DIFFERENCES \\
\hline Overall & $90 \%$ & $74 \%$ & $\mathrm{p}<0.05$ \\
Myopia & $100 \%$ & $97 \%$ & N.S. \\
Hypermetropia & $89 \%$ & $82 \%$ & N.S. \\
Astigmatic & $93 \%$ & $81 \%$ & $\mathrm{p}<0.01$ \\
Anisometropia & $71.5 \%$ & $95 \%$ & N.S. \\
\hline
\end{tabular}

Where: Sensitivity $=$ True positives/All positives

Specificity $=$ True negatives/All positives

The McNemar test was used to estimate the significance of differences.

Table VI Refractive thresholds for other screening methods

\begin{tabular}{|c|c|c|c|c|}
\hline & HYPERMETROPIA & MYOPLA & ASTIGMATISM & ANISOMETROPIA \\
\hline $\begin{array}{l}\text { Rapid retinoscopy } \\
\text { (Friedman et } \text { al }^{8} \text { ) } \\
\text { Photographic }\end{array}$ & +2.5 & -0.5 & 1.0 & 1.0 \\
\hline $\begin{array}{l}\text { Screening } \\
\text { (Kaakinen }^{10} \text { ) } \\
\text { Otago }\end{array}$ & +4.0 & -2.0 & significant & significant \\
\hline $\begin{array}{l}\text { Photoscreener } \\
\left(\text { Molteno et } \mathrm{al}^{11}\right)\end{array}$ & +5.0 & -2.0 & 1.0 & 1.0 \\
\hline $\begin{array}{l}\text { Photorefraction } \\
\text { (Atkinson et } \mathrm{al}^{12} \text { ) }\end{array}$ & +3.5 & -0.5 & 0.5 & 0.5 \\
\hline
\end{tabular}

method had an overall sensitivity of $93 \%$ and specificity of $82 \%$ evaluated in 161 children. Photorefraction by Atkinson et al ${ }^{14}$ in 1096 children aged 6 to 9 months included less than $1 \%$ false positives (anisometropia) and from a control sample of 52 of 975 'normal' only one false negative, an equivalent rate of $1.9 \%$ false negatives. Unlike Kaakinen's method there was no blind refractive interval.

Screening with simple retinoscopy is a quick method of screening refractive errors and anisometropia indicating those children who require full evaluation by an experienced retinoscopist. 


\section{Conclusions}

These results compare favourably with other more complex methods of screening and suggest that this test could be used by an orthoptist as an adjunct to vision screening in children under the direction of an ophthalmologist or community physician.

Full retinoscopy requires a skilled retinoscopist but this simple retinoscopy requires only very simple equipment, can easily be learnt and reliably used by an orthoptist who can handle children.

My thanks to Mr P A Graham FRCS for allowing me to do this study on his patients and for both his and Mrs S Sullivan FRCS contribution with the refractions, all the orthoptic staff at University Hospital, Wales who participated and Dr B Shine Moorfields Eye Hospital for his help with the data.

\section{References}

${ }^{1}$ Ingram RM: The problem of screening children for visual defects. Br J Ophthalmol 1977 61: 47.

${ }^{2}$ Ingram RM: Refraction as a basis for screening children for squint and amblyopia. $\mathrm{Br} J$ Opthalmol 1977 61: 8-15.

${ }^{3}$ Ingram RM: Screening for refractive errors at age one year: a pilot study. $\mathrm{Br} J$ Ophthalmol 1979 63: 243-50.

. Ingram RM, Walker C, Wilson JM, Arnold PE, Lucas $\mathrm{J}$ et al.: A first attempt to prevent amblyopia and squint by spectacle correction of abnormal refractions from age one year. $\mathrm{Br}$ J Ophthalmol 1985 69: 851-3.

${ }^{5}$ Ingram RM, Holland WW, Walker C, Wilson $\mathrm{JM}$ et al.: Screening for visual defects in preschool children Br J Ophthalmol 1976 70: 1621.
${ }^{6}$ Taylor DS: Screening? Trans Ophthalmol Soc UK 1985 104: 637-40.

7 Tommila V and Tarkkanen A: Incidence of loss of vision in the healthy eye in amblyopia. $\mathrm{BrJ}$ Ophthalmol 1981 65: 575-7.

${ }^{8}$ Freidman Z, Neumann E, Hyams SW, Peleg P: Ophthalmic screening of 38,000 chlidren, age one to 2 years in Child Welfare Clinics. J Paed Ophthalmol and Strab 1980 17: 261-5.

${ }^{9}$ Mohindra I: A non-cycloplegic refraction technique for infants and young children. $J$ Am Optom Assoc 1977 48: 518-23.

${ }^{10}$ Kaakinen K: A simple method for screening of children with strabismus, anisometropia or ametropia of children by simultaneous photography of the corneal and fundal reflexes. Acta Ophthalmol (Copenhagen) 1979 57: 60011.

${ }^{11}$ Molteno ACB, Hoare-Nairne J, Parr JC, Simpson A et al.: The Otago Photoscreener, a method for the mass screening of infants to detect squint and refractive errors. Trans Ophthalmol Soc NZ 1983 35: 43-9.

12 Atkinson J, Braddick OJ, Ayling L, PimmSmith E: Isotropic photorefraction: a new method for refractive testing of infants. Doc Ophthalmol Proc Ser 1981 30: 217-23.

${ }^{13}$ Atkinson J, Braddick OJ: Vision screening and photorefraction - the relation of refractive errors to strabismus and amblyopia. Behav Brain Res 1983 10: 71-80.

${ }^{14}$ Atkinson J, Braddick OJ, Durden K, Watson PG et al.: Refractive Screening of 6-9 month olds using photorefraction. Br J Ophthalmol 1984 68: 105-12.

${ }^{15}$ Sjöstrand J, Abrahamsson M, Fabian G, Wennhall O: Photorefraction: a useful tool to detect refractive errors Acta Ophthalmol (Copenhagen) Suppl 1982 157: 46-52. 